\title{
A INSTITUCIONALIZAÇÃO DO CONSELHO DE PESQUISAS NO BRASIL: INSPIRAÇÕES HISTÓRICAS INTERNACIONAIS E IDENTIDADE PARA A CONCEPÇÃO DAS ÁREAS DO CONHECIMENTO
}

\author{
LA INSTITUCIONALIZACIÓN DEL CONSEJO DE \\ INVESTIGACIÓN EN BRASIL: INSPIRACIONES \\ HISTÓRICAS INTERNACIONALES E IDENTIDAD PARA \\ LA CONCEPCIÓN DE LAS ÁREAS DEL CONOCIMIENTO
}

Angelica Alves da Cunha Marques*

RESUMO:

Introdução: Considera a escassez de registros históricos acerca da trajetória do Conselho Nacional de Pesquisas no Brasil, hoje CNPq, bem como da noção de que a instituição teria sido inspirada na sua congênere francesa. Objetivo: Este artigo objetiva apresentar as inspirações históricas no contexto internacional, especialmente na França, e a formação da identidade institucional desse Conselho. Metodologia: Trata-se de uma pesquisa bibliográfica e documental, cujos referenciais teóricos assentam-se nos conceitos de "prestígio internacional" e de "capital científico". Resultados: Como resultados dessa pesquisa, apresenta um breve histórico dos conselhos de pesquisa dos Estados Unidos, do Canadá, do Reino Unido e, especialmente, da França, bem como das suas principais divisões atuais, relacionadas às classificações das áreas do conhecimento. Apresenta, ainda, a trajetória de concepção, criação e desenvolvimento do $\mathrm{CNPq}$, as áreas do conhecimento reconhecidas pela instituição ao longo do tempo, discutindo aspectos de aproximação aos conselhos internacionais, suas inspirações tendo em vista o prestígio internacional dessas instituições, e as suas particularidades, mediante o capital científico político e institucional. Conclusões: Conclui que os aspectos políticos e institucionais predominam no estabelecimento do Conselho Nacional de Pesquisas no Brasil, uma vez que as inspirações internacionais são variadas e não parecem se traduzir na identidade institucional que se alinha ao contexto nacional.

Palavras-chave: Conselho Nacional de Pesquisas. CNPq. Áreas do conhecimento. História da Ciência. Ciência e Tecnologia.

*Doutora em Ciência da Informação. pós-doutoramento junto ao Programa de Pós-graduação em Ciência da Informação (UnB) e à École Nationale des Chartes (Paris). Professora do Programa de Pós-graduação em Ciência da Informação da UnB. E-mail: angelicacunha@unb.br 


\section{INTRODUÇÃO}

A relação entre a ciência e a guerra é antiga. Com a I Guerra Mundial, há o reconhecimento da eficácia da Ciência \& Tecnologia (C\&T) para a definição das batalhas. Nessa perspectiva, surgem as fundações particulares para incentivo à C\&T, como a Rockefeller, a Carnegie e a Ford, bem como as ideias de criação de vários conselhos de pesquisa, no âmbito de políticas nacionais para a C\&T. Internacionalmente, existem movimentos pela criação dessas instituições, embalados pela ideologia da centralização e da planificação, como nos Estados Unidos, no Canadá e na Grã-Bretanha, no início do século XX (MOTOYAMA, 1985; MOTOYAMA; NAGAMINI, 1996).

A conjugação das intervenções armadas com a política externa que marca o século $X X$ culmina na difusão das influências das grandes potências. No Brasil, podemos verificar o prestígio da cultura francesa. Aqui, como lá, o Positivismo, representado por Auguste Comte, tem influência. Na França, contudo, esse contexto é marcado pela falta de destaque da pesquisa frente ao ensino, pela decadência do sistema de cátedras, pela pouca adesão ao exemplo do instituto. Mais especificamente, verifica-se um atraso em ciência aplicada: no meio universitário, a pesquisa fundamental tem prestígio, enquanto a pesquisa utilitária é concebida, por vezes, como "impura" (MOTOYAMA; NAGAMINI, 1996). Nesse país, a primeira instituição congênere a um conselho de pesquisa é do início desse século, embora com o nome que a conheçamos hoje seja dos anos 1930 - Conseil National de la Recherche Scientifique (CNRS).

No Brasil, a ideia embrionária de um conselho de pesquisa surge nos anos 1920, inspirada no caso francês, mas não exclusivamente, como veremos na seção 3 deste artigo.

Este artigo tem por objetivo apresentar as inspirações históricas do contexto internacional, especialmente da França, e a formação da identidade institucional do Conselho de Pesquisas no Brasil, hoje Conselho Nacional de 
Desenvolvimento Científico e Tecnológico (CNPq), diante da escassez de estudos sobre o tema. ${ }^{1}$ Para a consecução deste objetivo, realizamos pesquisa bibliográfica e documental no fundo CNPq, custodiado pelo Museu de Astronomia e Artes Afins (MAST) e pelo próprio Conselho, cujos referenciais teóricos retomaram os conceitos de "prestígio internacional" (ROMANI, 1982; ANDRADE, 1998), tendo em vista a compreensão das inspirações históricas e, do "capital científico" (BOURDIEU, 2001), para o estabelecimento do Conselho Nacional de Pesquisas.

Sobre o prestígio internacional, Romani lembra que este fora, outrora, "elemento propulsor do amparo estatal à ciência", já em 1808: "o apoio estatal oferecido às 'expedições aqui encetadas por cientistas europeus contribuía para a imagem de uma monarquia esclarecida e culta, compatível com os laivos de refinamento da elite proprietária"' (PEREIA apud ROMANI, 1982, p. 142). ${ }^{2}$ É nesse sentido que assistimos, ao longo de séculos, a missões científicas desdobrarem-se no solo brasileiro, encomendadas pelo Estado (SCHWARTZMAN, 1979).

Contudo, como esclarece Azevedo (1994), nem mesmo a atuação de Dom João VI (1808-1821) - inauguração do ciclo das viagens e das expedições científicas; abertura às trocas de mercadorias, à imigração de pessoas, às experiências e aos costumes e à transformação dos velhos hábitos coloniais; lançamento das bases para as escolas técnico-profissionais - e a emancipação política do País (1822) alteram a situação de falta de renovação. Ao fazer um balanço das iniciativas e realizações do Segundo Império, o autor pontua que o desenvolvimento científico é irregular e se destaca num ou noutro

\footnotetext{
1 Este trabalho decorre de pesquisa de pós-doutoramento realizada no Brasil e na França, entre 2014 e 2015, o qual, por sua vez, parte dos resultados de um longo projeto de pesquisa sobre a trajetória da Arquivologia como disciplina no Brasil, suas relações com outras disciplinas e suas interlocuções internacionais.

2 PEREIRA, Maria Cândido. Reflexões sobre Estado, Ciência e Tecnologia. Mimeo, FINEP, Rio de Janeiro, 1976.
} 
setor, como na Botânica, Zoologia, Astronomia e Matemática. Azevedo lembra que a única ciência com uma tradição brasileira é a Botânica. Nesse quadro, ele retoma as contribuições de vários estrangeiros que vêm ao Brasil em expedições desde 1810, embora destaque a limitação dessas contribuições.

Romani (1982, p. 137) explica que o prestígio internacional na criação do Conselho Nacional de Pesquisas atua "como fator de fortalecimento da imagem do Estado enquanto agente modernizador". Nesse sentido, "O quadro de referência que orientou a atuação inicial do Conselho, advinha, em grande parte, da experiência de órgãos internacionais", dos quais a autora destaca instituições dos Estados Unidos e da França, observando que "as primeiras ações deste órgão, incorporando a orientação internacional, constituem-se, de certo modo, numa forma de aprendizagem dos caminhos a seguir na transposição daqueles mecanismos estrangeiros ao Brasil, mais do que em ações decorrentes de propósitos e intenções cristalizadas" (ROMAINI, 1982, p. 143).

Dentre os propósitos deste trabalho, nos propomos a retomar pistas históricas a fim de compreender os processos de institucionalização do Conselho Nacional de Pesquisas no Brasil, para além da noção largamente recorrente de que este teria se inspirado exclusivamente no órgão congênere francês. Assim, é também importante recorrermos ao conceito de "capital científico", proposto por Bourdieu (2001; 2004). De acordo com esse estudioso, a estrutura do campo científico é constituída e perpassada pela acumulação de uma forma específica de capital, o capital científico, cujas espécies são: 1) o temporal, ou político, que contempla os interesses comuns, o consenso mínimo, a defesa de interesses coletivos e os eventos internacionais; 2) e o intelectual ou propriamente científico.

O capital científico temporal é adquirido por estratégias políticas e distintas formas de transmissão e segue as mesmas regras de transmissão que qualquer outra espécie de capital burocrático, embora possa assumir a aparência de uma "eleição" (BOURDIEU, 2004). Esse tipo de capital relacionase mais às instâncias nacionais, às instâncias temporariamente dominantes e 
dependentes de autoridades temporais, sejam elas econômicas ou políticas (BOURDIEU, 2001).

O capital científico "puro", predominantemente internacional, é, por sua vez, adquirido pelas contribuições reconhecidas ao progresso da ciência, como as invenções ou descobertas e diz respeito às habilidades pessoais. Por isso, é difícil de transmitir na prática. Ainda que legitime o campo científico, não se aplica diretamente ao objeto deste trabalho.

Considerando as ponderações de Romani (1982) quanto ao prestígio internacional e as características do capital científico político, parece-nos que a conjugação desses dois aspectos podem nos auxiliar na compreensão dos processos de institucionalização do Conselho Nacional de Pesquisas no Brasil.

A atribuição de prioridades à ciência mediante a formulação de políticas científicas e a concretização das mesmas dependem, em último termo, da função social atribuída à ciência. Desta forma, é na organização social do país e no processo histórico de sua formação que se deve buscar os elementos básicos, responsável pela estrutura da produção científica entendendo-se por estrutura os processos nos quais os conhecimentos científicos são produzidos, circulam e são incorporados à sociedade. Tais processos, nos quais o Estado desempenha papel fundamental tanto no nível da produção quanto da incorporação - são processos institucionais. (ROMANI, 1982, p. 165).

\section{CONSELHOS DE PESQUISA MUNDO AFORA}

Os países que teriam inspirado o Brasil, na institucionalização do seu Conselho Nacional de Pesquisas, segundo as obras consultadas em nossa pesquisa bibliográfica, são os Estados Unidos, o Canadá, o Reino Unido e a França (ROMANI, 1982; MOTOYAMA, 1985; MOTOYAMA; NAGAMINI, 1996; ANDRADE, 1998). A seguir, apresentaremos um breve histórico dos conselhos desses países, bem como das suas principais divisões atuais que podemos relacionar às classificações das áreas do conhecimento, detendo-nos um pouco mais no caso francês, tido como principal inspirador do CNPq no Brasil.

Nos Estados Unidos, a National Academy of Sciences (NAS) nasce no contexto da Guerra Civil, com o ato constitutivo, assinado pelo presidente 
Lincoln, em 3 de Março de 1863, que estabelece seu serviço à nação e nomeia 50 membros fundadores. Ao longo dos anos, a instituição amplia seus serviços para o Governo. Com o aumento do volume de pedidos de aconselhamento em matéria de preparação militar durante a I Guerra Mundial, a Academia cria o National Research Council (NRC), em 1916, a pedido do Presidente Wilson, para recrutar especialistas das comunidades científicas e tecnológicas maiores para participar desse trabalho. Em 1918, começa a ser difundida a ideia de se formar uma entidade internacional nesse sentido (MOTOYAMA, 1985). Anos mais tarde, sob a autoridade do seu estatuto social, a NAS estabelece a National Academy of Engineering, em 1964, e o Institute of Medicine, em 1970, que se tornou a National Academy of Medicine, em 2015. Essas organizações são compostas por membros eleitos pelos seus pares, em reconhecimento da realização distinta em seus respectivos campos. ${ }^{3}$

A National Academies of Sciences, Engineering, and Medicine possui, atualmente, sete programas: 1) Ciências Sociais e Comportamentais e Educação; 2) Estudos da Terra e da Vida; 3) Engenharias e Ciências Físicas; 4) Instituto de Medicina; 5) Política e Assuntos Globais; 6) Comitê de Pesquisa em Transporte; 7) e o Programa de Pesquisas do Golfo. ${ }^{4}$

No Canadá, o Conseil National de Recherches (CNRC) é o principal órgão de pesquisa e desenvolvimento do Governo. É associado à indústria e promove a divulgação da pesquisa do laboratório, de modo a aplicá-la comercialmente, beneficiando a população. Nesse sentido, o pessoal, o conhecimento, os serviços, as licenças de exploração, as instalações nacionais e as redes internacionais apoiam as empresas canadenses, por meio de programas de pesquisa e desenvolvimento (R-D) estratégicos. ${ }^{5}$

3 Informações disponíveis em: <http://www.nationalacademies.org/about/history/index.html>. Acesso em 08 mar. 2016. (Tradução nossa)

${ }^{4}$ Informações disponíveis em: <http://www.nationalacademies.org/about/whatwedo/index.html>. Acesso em 08 mar. 2016. (Tradução nossa)

5 Informações disponíveis em: <http://www.nrc-cnrc.gc.ca/fra/apropos/index.html >. Acesso em 09 mar. 2016. (Tradução nossa) 
O CNRC possui três divisões integradas de R-D, dirigidas pelos órgãos consultivos de chefes da indústria. Dentro dessas três divisões, há 12 setores integrados, agrupados e ligados aos domínios industriais prioritários: 1) Tecnologias emergentes, que compreendem as Tecnologias de informação e comunicação; a Ciência de Medidas e Escalas; o CNRC Hezberg, Astronomia e Astrofísica; e as Tecnologias de Segurança e de Ruptura; 2) as Ciências da Vida, que se desdobram no Desenvolvimento de culturas e de recursos aquáticos; Terapêuticas em saúde humana; e Dispositivos médicos; 3) a Engenharia, dividida em Aeroespacial; Automóvel e transporte de superfície; Construção; Energia, minas e meio ambiente; e Engenharia oceânica, costeira e fluvial. ${ }^{6}$

No Reino Unido, o Research Councils UK (RCUK) integra os conselhos de pesquisa, que sob o guarda-chuva RCUK, buscam trabalhar em conjunto tendo em vista benefícios para suas comunidades acadêmicas, para o Governo e para outras partes interessadas em fazê-lo. Assim, a instituição busca otimizar os trabalhos dos conselhos de pesquisa, para melhorar o desempenho global e o impacto da pesquisa no Reino Unido, a formação e a transferência de conhecimentos, bem como o reconhecimento pela academia, pelas empresas e pelo governo para a excelência no patrocínio de pesquisa. ${ }^{7}$

Atualmente, existem sete conselhos de pesquisa, responsáveis por investir o dinheiro público na pesquisa no Reino Unido, para o avanço do conhecimento e a geração de novas ideias: 1) Artes e Humanidades, que abrange História (antiga, medieval e moderna); Clássicos; Arqueologia; Línguas modernas e Linguística; Língua inglesa e Literatura; Artes visuais e meios de comunicação; Estudos de Biblioteconomia, de informação e de museus; Filosofia, Direito e estudos religiosos; e Música e artes cênicas e

\footnotetext{
${ }^{6}$ Informações disponíveis em: <http://www.nrc-cnrc.gc.ca/fra/apropos/vue ensemble/index.html >. Acesso em 09 mar. 2016.

7 Informações disponíveis em: <http://www.rcuk.ac.uk/about/aboutrcuk/aims/>. Acesso em 09 mar. 2016
} 
criativas; 2) Biotecnologia e Ciências Biológicas, composto por Genomas, Biologia das células estaminais e Bio-nanotecnologia; Biologia geral; Biologia das populações e dos sistemas que sustentam a agricultura, a biodiversidade e os novos processos de base biológica e renováveis de energia e de produção; 3) Engenharia e Ciências Físicas, que compreendem a Matemática; Química; Física; Ciência de materiais; Engenharia; Ciência da computação; Pesquisa sobre energia; Pesquisa sobre o ambiente construído; Tecnologia da informação e comunicação; Pesquisa sobre produção inovadora; 4) Pesquisa Econômica e Social, por sua vez composta pela Sociologia; Economia; Antropologia; Ciência Política; Área ou pesquisa baseada em região e geografia; Relações internacionais; Estudos culturais e meios de comunicação; Lei e Linguística; e Psicologia; 5) Conselho de Pesquisa Médica, que contempla o Uso de animais em pesquisa; a Resistência a antibióticos; as Ciências do cérebro; Genomas e proteínas; Saúde pública; Cuidados intensivos; Segurança do paciente; Pesquisa sobre células estaminais; 6) Pesquisa sobre ambiente natural, desdobrada na Geografia e Ciências da terra, Hidrologia, Ciência do solo, Pesquisa atmosférica e oceanografia; Pesquisa biológica e microbiológica em biodiversidade animal e vegetal, Dinâmica populacional e ecologia; Pesquisa sobre alterações climáticas; Química e física do meio ambiente; Observação da Terra por satélite; Pesquisa polar; Gestão da terra e dos recursos naturais; 7) Instalações Científicas e Tecnológicas, compostas pela Astronomia; Ciência da computação; Energia; Física nuclear; Física das partículas; e Ciência espacial. ${ }^{8}$

Na França, em 1901, é criada a Caisse de Recherches Scientifiques (CRS), com o objetivo de equipar os laboratórios. São realizados investimentos externos em institutos franceses e grupos de cientistas passam a defender a criação de um conselho nacional de pesquisas, bem como a valorização dos pesquisadores. Em 1922, é criado o Office Nationale des Recherches

\footnotetext{
8 Informações disponíveis em: <http://www.rcuk.ac.uk/about/Aboutrcs/>. Acesso em 09 mar. 2016.
} 
Scientifiques et des Inventions (ONRSI), com conselho nacional de 148 membros (cientistas e industriais, eleitos pelo Parlamento) (MOTOYAMA; NAGAMINI, 1996). Quatro anos mais tarde, em 1926, a Union Racionaliste dá voz àqueles que acreditavam na política interdisciplinar para encaminharem a luta para a criação do conselho de pesquisas. É, então, proposto o estabelecimento de um sistema de bolsas sob responsabilidade dos poderes públicos. Parece-nos que aí estaria a gênese do conselho de pesquisas (futuro CNRS), o qual, por sua vez, inspiraria, anos mais tarde, o CNPq no Brasil:

\begin{abstract}
Isso deveria incentivar os jovens pesquisadores, dando-lhes um meio de sobrevivência, e facilitaria a vinda dos cientistas estrangeiros, pois pagaria a sua remuneração. Estatuíam também um conselho superior, constituído por representantes das áreas científicas, com a função de definir as formas de avaliação, assim como as prioridades. (MOTOYAMA; NAGAMINI, 1996, p.341).
\end{abstract}

$\mathrm{Na}$ década de 1930 há esforços da comunidade científica para a implementação de um sistema de bolsas de estudos para incentivar jovens pesquisadores. Mais especificamente, em 1930, há o encaminhamento de um projeto de um Service National de la Recherche Scientifique. A Caisse Nationale des Sciences (CNS) é criada no mesmo ano. Em 1933, é criado o Conseil Supérieur de la Recherche Scientifique (CSRS), com oito seções, "sendo essa distribuição fortemente inspirada no sistema universitário da época" (MOTOYAMA; NAGAMINI, 1996, p. 342): seis relativas às Ciências Exatas (Matemática, Mecânica e Astronomia, Física, Química, Biologia e Ciências Naturais); e duas às Ciências Humanas (História e Filologia, Filosofia e Ciências Sociais). No ano seguinte, em 1934, o CRS e a CNS se unem no CNRS e é criado um subsecretariado de Estado de Pesquisa Científica, com um serviço central para a organização dos corpos de ajuda técnica. Em 1938, é criado o Centre de la Recherche Scientifique Appliqueé (CNRSA) para substituir o antigo ONRSI. Em 1939, legislação sobre normas de funcionamento e gestão dos laboratórios e do estabelecimento do ensino superior direciona o futuro do CNRS, com a previsão de comitês de direção e 
de bolsas de auxílio à pesquisa. No mesmo ano, o CNRSA, a CNS e o serviço central se unem em torno do CNRS:

\begin{abstract}
Surge finalmente, o CNRS. Este cumpriria a função de remunerar pesquisadores e de assegurar os serviços de ajuda técnica; estudar as necessidades e possibilidades da formação de novos laboratórios; coordenar as atividades dos laboratórios no país; estabelecer e prestar serviços junto aos poderes públicos; e de responder, ainda, pelos serviços auxiliares indispensáveis ao desenvolvimento da pesquisa. Contudo, essas funções só foram plenamente implantadas depois da Segunda Guerra, porquanto a França foi invadida pelos alemães, ficando sob o seu domínio até quase o término dela. Pode-se dizer que o verdadeiro início do CNRS coincide com o renascer da França dos escombros do conflito militar. A esperança de um novo tempo dos pesquisadores franceses era a de todos os franceses por um porvir radiante e fecundo. $O$ novo órgão encarnava essa esperança. (MOTOYAMA; NAGAMINI, 1996, p.344).
\end{abstract}

Hoje, o CNRS caracteriza-se como um organismo público de pesquisa, subordinado ao Ministério da Educação Nacional, de Ensino Superior e da Pesquisa. É composto por dez institutos: Instituto de Ciências Biológicas, Instituto de Química, Instituto de Ecologia e Ambiente, Instituto de Ciências Humanas e Sociais, Instituto de Ciências da Informação e suas interações, Instituto de Ciências de Engenharia e de Sistemas, Instituto Nacional de Ciências Matemáticas e de suas interações, Instituto de Física, Instituto Nacional de Física Nuclear e de Física de Partículas e Instituto Nacional de Ciências do Universo. ${ }^{9}$

\title{
3 CNPq: DE "CASA DO CIENTISTA" A "ESTEIO DO BRASIL MODERNO"
}

Para compreendermos a trajetória do CNPq, devemos, como nos aconselha Domingos (2004), apreender os processos sócio-políticos brasileiros ao longo da sua história, na atuação da comunidade de pesquisadores e do

\footnotetext{
9 Informações disponíveis em: <http://www.cnrs.fr/fr/organisme/presentation.htm>. Acesso em 09 mar. 2016.
} 
poder, segundo orientações dos seguimentos sociais politicamente hegemônicos. Nesse sentido, precisamos retomar um contexto de saberes prestigiados, sobretudo até 1930.

Criada em 1916, a Sociedade Brasileira de Ciências (SBC) configura-se como uma organização da comunidade científica para levar avante as suas reivindicações e fortalecer os seus laços internos. Privilegia a ciência pura, como um antídoto contra a postura prático-imediatista (MOTOYAMA, 1985). Nessa perspectiva, a SBC tinha por objetivo "estimular a continuidade do trabalho científico de seus membros, o desenvolvimento da pesquisa brasileira e a difusão do conceito de ciência como fator fundamental do desenvolvimento tecnológico do país". ${ }^{10}$ Ainda que tivesse um objetivo tão amplo, a instituição abrangia apenas três seções: Ciências Matemáticas, Ciências Físico-químicas e Ciências Biológicas, a exemplo da Academia Francesa de Ciências. ${ }^{11}$

Em 1919, a SBC, depois Academia Brasileira de Ciências (ABC), em 1921, é convidada a participar de um congresso do International Research Council (IRC). Contudo, não recebe o necessário apoio da sociedade brasileira e os pesquisadores brasileiros não chegam a participar do evento. É importante pontuar que, segundo Motoyama e Nagamini (1996), parte da ABC valorizava a Ciência Pura, como na França.

Em 1923, a ABC adere-se ao IRC, o qual tem vida efêmera (MOTOYAMA, 1985). Alguns anos mais tarde, em 1926, a ABC participa do evento desse Conselho e amadurece a ideia da necessidade de formação de um conselho de pesquisas. Nesse contexto, recebe o apoio de pesquisadores, cientistas e políticos, dentre os quais Álvaro Alberto da Motta e Silva e Miguel

10 Informações disponíveis em: <http://www.abc.org.br/article.php3?id_article=4>. Acesso em 10 mar. 2016.

11 Hoje a ABC contempla dez áreas: Ciências Agrárias, Ciências Biológicas, Ciências Biomédicas, Ciências da Saúde, Ciências da Engenharia, Ciências da Terra, Ciências Físicas, Ciências Humanas, Ciências Matemáticas e Ciências Químicas. Informações disponíveis em: <http://www.abc.org.br/article.php3?id_article=6>. Acesso em 10 mar. 2016. 
Osório de Almeida, participantes de congressos do IRC, que acalentam a ideia de um conselho de pesquisa no Brasil. Contudo, falta apoio político e do próprio Estado e fica evidente a necessidade de articulação entre cientistas e políticos, novamente a exemplo da França (MOTOYAMA, 1985; MOTOYAMA; NAGAMINI, 1996).

Assim, a ideia embrionária de um conselho de pesquisa brasileiro parece surgir na ABC (CONSELHO NACIONAL DE PESQUISA E DESENVOLVIMENTO CIENTÍFICO E TECNOLÓGICO, 1984). A associação entre o cientista e o estadista de larga visão aparece como vital para a implementação da C\&T no Brasil. Exemplos icônicos, nesse sentido, são as figuras de Oswaldo Cruz e Rodrigues Alves (MOTOYAMA, 1985), intelectuais que marcariam a história da ciência brasileira.

Em 1924, é criada a Associação Brasileira de Educação (ABE), a qual, juntamente da $\mathrm{ABC}$, organizam o Ministério da Educação e Saúde Pública (1930) e criam o Conselho Nacional de Educação (CNE), no ano seguinte. A ABC sugere, ainda em 1931, a criação de um conselho de pesquisas, ao enviar um memorial ao Governo, mas esta sugestão não se concretiza (CONSELHO NACIONAL DE PESQUISA E DESENVOLVIMENTO, 1981a; 1981b; ROMANI, 1982; MOTOYAMA, 1985; MOTOYAMA; NAGAMINI, 1996).

Em 1934 é criada a Universidade de São Paulo (USP), na qual é concebida a Faculdade de Filosofia, Ciências e Letras (FFCL). No mesmo ano é criada a Universidade do Distrito Federal (UDF) (MOTOYAMA, 1985; MOTOYAMA; NAGAMINI, 1996).

Em 1936, o Presidente da República, Getúlio Vargas, encaminha, ao Congresso Nacional, mensagem sobre a possibilidade de criação de um Conselho Nacional de Pesquisas Experimentais, para apoiar atividades agrícolas. Inspirado no exemplo norte-americano, a instituição exploraria racionalmente as riquezas agrícolas do país. Entretanto, essa entidade não é criada (ROMANI, 1982; MOTOYAMA, 1985; MOTOYAMA; NAGAMINI, 1996).

Nesse contexto, Romani (1982, p. 137) atrela a ideia de criação de um Conselho Nacional de Pesquisas à questão do "prestígio internacional". 
Segundo ela, a instituição "atuaria assim como fator de fortalecimento da imagem do Estado enquanto agente modernizador".

Carlos Chagas Filho teria se entusiasmado com o movimento dos cientistas franceses em torno do CNRS. A recém-criada instituição (1934) teria se concretizado em decorrência dos esforços de um grupo "brilhante" de cientistas, dedicados à revitalização na pesquisa na França (MOTOYAMA, 2004, p. 269). Como explicam Motoyama e Nagamini:

Apesar dessas tentativas malogradas, o grupo reunido em torno da ABC continuou fazendo pesquisa pelo conselho. Em 1938, Carlos Chagas, do Laboratório de Biofísica da Faculdade de Medicina da Universidade do Brasil, ao retornar de um estágio realizado na França, propôs a criação de um órgão similar ao existente naquele país. Tratava-se da então Caisse Nationale de la Recherche Scientifique.

Entusiasmado com o sucesso da Caisse, Chagas Filho entrega toda a documentação relativa a essa instituição, juntamente como um projeto de criação de um órgão semelhante no Brasil, ao ministro da Educação, Gustavo Capanema. Todavia, nunca mais se teve notícia dessa documentação, que se perdeu no labirinto dos corredores da administração federal. (MOTOYAMA; NAGAMINI, 1996, p.348).

Dentre as dificuldades apresentadas por esses autores, está a falta de repercussão dessa campanha nos meios políticos e governamentais, diante do modelo centralizador do governo Vargas e da "tradição prático-imediatista" (MOTOYAMA; NAGAMINI, 1996). Motoyama (1985) explica que a ideologia do planejamento e a tecnocracia alemã, norte-americana e inglesa da década de 1930 teriam inspirado o Brasil. Em 1942, é criada a Coordenação de Mobilização Econômica (CME), tendo em vistas a "planificação nacional".

O Brasil participa da Comissão de Energia Atômica da Organização das Nações Unidas (ONU), representado pelo então Capitão de mar e guerra, Álvaro Alberto da Motta e Silva, entusiasta do Conselho Nacional de Pesquisas (1940). Ele propõe uma comissão para organizar um Conselho Nacional de Energia Atômica, ao conceber nesse tipo de instituição um instrumento para fortalecer o potencial científico e tecnológico autônomo, para obtenção de energia nuclear (MOTOYAMA; NAGAMINI, 1996). 
O presidente da $A B C$ declara, como uma das suas metas, ajudar no estabelecimento de um órgão semelhante ao conselho, citando o relatório do Office of Scientific Research and Development (OSDR) norte-americano. Havia, portanto, interesse em organizar uma instituição similar à Atomic Energy Commission (ANDRADE, 1998).

Por outro lado, no contexto da II Guerra Mundial, são criados os Fundos Universitários de Pesquisa (FUP) para a defesa Nacional. Estes recebem amplo apoio e obtêm sucesso (MOTOYAMA; NAGAMINI, 1996).

\begin{abstract}
A Segunda Guerra Mundial, no entanto, contribuiu para mudar drasticamente a concepção e as formas de institucionalização da ciência. Centralizadas em países industrializados da Europa e América do Norte, políticas científicas e tecnológicas passaram a ser formuladas tendo em vista o crescimento da economia e o fortalecimento do poder político-militar. No Brasil - onde a ciência, fragilmente organizada, estava restrita a poucos e a pequenos núcleos de investigação no Rio de Janeiro e São Paulo - as aspirações e o modelo vinham daqueles países. (ANDRADE, 1998, p.11).
\end{abstract}

A repercussão da energia atômica e a necessidade de pesquisas nucleares remetem, novamente, à necessidade de criação de um Conselho Superior de Pesquisas (MOTOYAMA; NAGAMINI, 1996).

A comunidade científica nos anos 1940, ainda pequena, é aberta à política de atração de cientistas estrangeiros para nuclearem grupos de investigação científica.

Outrossim, o esforço de quem despertara a confiança dos cientistas na sua capacidade para o desenvolvimento geral da nação. Tendo como pano de fundo esse panorama nacional e internacional, a comunidade científica brasileira, muito motivada, abriria uma série de baterias, reivindicando melhores condições de trabalho e de financiamento para as pesquisas. (MOTOYAMA, 1985, p.36).

Carlos Chagas Filho, em uma nova tentativa, publica, em um dos boletins da UNESCO (1946), um artigo sobre a importância de um conselho de pesquisas.

Nesse contexto, formação teórica e formação prática são concebidas distintamente. O relatório de Vannevar Bush, "Science, the endless frontier", 
apresenta a ciência básica como o capital científico que deveria ser libertado da dependência europeia (MOTOYAMA, 1985).

O texto "Ciência e pesquisa", distribuído entre os constituintes, em 1947, apresenta o dever do Estado em amparar a ciência e a necessidade de estabelecer uma fundação por meio da Constituição, ao retomar a experiência dos Estados Unidos, da União Soviética, da Inglaterra e da França (MOTOYAMA, 1985).

"O advento inesperado da 'era atômica' trouxera um novo alento a Academia para a concretização do velho sonho do conselho de pesquisas" (MOTOYAMA, 1985, p. 38). Em 1947, em seu relatório de missão na ONU, Álvaro Alberto ratifica: "Fundação do Conselho Nacional de Pesquisas, para fomentar e coordenar as atividades científicas e técnicas, escolher pessoal idôneo e ser imediatamente encaminhado ao estrangeiro para aperfeiçoamento" (MOTOYAMA, 1985, p. 39).

Em 1948 é criada a SBPC. No mesmo ano, acontece a Conferência dos Peritos Científicos da América Latina, em Montevidéu. Álvaro Alberto insiste na sua proposta, mencionando as entidades do Canadá, da Inglaterra, dos Estados Unidos e da França. "Um dos modelos mais discutidos foi o do Canadá, pois ele respondia também pela questão da energia atômica, tal como se daria no caso brasileiro" (MOTOYAMA; NAGAMINI, 1996, p. 355). Esse projeto centrado na perspectiva da energia atômica é abandonado, provavelmente em decorrência da inspiração nas experiências estrangeiras, que tinham uma proposta de conselho com atuação mais ampla (ROMANI, 1982).

No ano seguinte, em 1949, o Presidente Dutra nomeia uma comissão de 22 membros, presidida por Álvaro Alberto, a qual se dedica ao trabalho de um anteprojeto de lei, apresentado ao Congresso no mesmo ano, propondo "a criação de um órgão de supervisão que se apresenta como um Estado-Maior da Ciência, da Técnica e da Indústria, neste particular 'capaz de traçar rumos seguros aos trabalhos de pesquisas científicas e tecnológicas no país, desenvolvendo-os e coordenando-os de modo sistemático'” (ROMANI, 1982, p. 139). 
Finalmente, em 15 de janeiro de 1951, é criado o Conselho Nacional de Pesquisas, pela Lei $1.310,{ }^{12}$ como uma autarquia diretamente vinculada à Presidência da República, como a Atomic Energy Commission, dos Estados Unidos: "É criado o Conselho Nacional de Pesquisas, que terá por finalidade promover e estimular o desenvolvimento da investigação científica e tecnológica em qualquer domínio do conhecimento" (BRASIL, 1951a, grifos nossos).

O Decreto n. 29.433/51 reforça esta abrangência ilimitada em seu art. $1^{0}$ :

O Conselho Nacional de Pesquisas, (C. N. Pq.) tem por finalidade promover e estimular o desenvolvimento da investigação científica e tecnológica em qualquer domínio do conhecimento, tendo em vista o bem estar humano e os reclamos da cultura, da economia, e da segurança nacional. (BRASIL, 1951b, grifos nossos).

Contudo, o mesmo decreto, ao apresentar a estruturação da Divisão Técnico Científica, restringe-se a oito setores (art. 17): 1) Técnico; 2) de Pesquisas Físicas; 3) de Pesquisas Matemáticas; 4) de Pesquisas Químicas; 5) de Pesquisas Biológicas: 6) de Pesquisas Geológicas; 7) de Pesquisas Agronômicas; 8) de Pesquisas Tecnológicas.

Assim, "Embora suas finalidades digam respeito a pesquisas em qualquer ramo do conhecimento, foi julgado preferível, no início de seu funcionamento, voltar principalmente a atenção do C. N. Pq. para os ramos básicos da ciência" (CONSELHO NACIONAL DE PESQUISAS, 1952, p. 8).

O projeto de Regimento Interno (1954) ratifica, mais uma vez, a amplitude de atuação do CNPq: "investigação científica e tecnológica em qualquer domínio do conhecimento" (informação confirmada na versão

12 Legislação sobre a criação (Lei n. 1310/51, de 15/01/51) e transformação (Lei n. 6.129/74, de 06/11/74) do CNPq, bem como decreto de regulamentação do Órgão (Decreto n. 29.433/51, de 04/04/51). Inclui rascunhos de alterações propostas à lei de criação e à minuta da Lei 4.533/64, de 08/12/64. - Rio de Janeiro, 1951 a 1975. 7 d., 88f, 1 cópia. (Fundo CNPq CNPq.T.1.1.002). 
aprovada do documento, de 03 de março de 1955). ${ }^{13}$ A Divisão Técnicocientífica continua com oito setores, sendo o último deles de Fiscalização do Material Radioativo. A fim de suprir demandas de outras áreas, o parágrafo único do Art. 18 enuncia: "Para atender ao desenvolvimento de suas atividades, poderão ser criados novos setores na D.T.c., por decisão do Conselho Deliberativo".

Já a versão aprovada do Regimento altera esses setores para: 1) Agricultura; 2) Biologia e Ciências Médicas; 3) Ciências Sociais; 4) Ciências da Terra; 5) Física e Astronomia; 6) Matemática; 7) Veterinária; 8) Química; 9) e Tecnologia.

Informação quanto aos setores é ratificada no Projeto de Decreto, de 1959, que aprova o Regulamento do Conselho Nacional de Pesquisas. A minuta da Lei 4.533/64, de 08 de dezembro de 1964 confirma a abrangência do $\mathrm{CNPq}$ em relação a todas as áreas do conhecimento, que passa a contemplar três câmaras que orientariam as reuniões do Conselho Deliberativo: Câmara de Pesquisa Básica, Câmara de Pesquisa Aplicada e Câmara de Pesquisa Tecnológica. O Departamento Técnico-científico passa a se compor de nove setores, assim discriminados: 1) Agricultura; 2) Biologia e Ciências Médicas; 3) Ciências Sociais; 4) Ciências da Terra; 5) Física e Astronomia; 6) Matemática; 7) Veterinária; 8) Química; 9) Tecnologia (St. T) (BRASIL, 1965). Os mesmos setores são elencados no Regimento do CNPQ (Diário Oficial de $1^{\circ}$ de fevereiro de 1966; aprovado na Sessão 809ª de 15 de dezembro de 1965, do Conselho Deliberativo).

Quanto à posição política do CNPq na sua criação (autarquia diretamente vinculada à Presidência da República), Andrade (1998) afirma que essa posição Ihe propicia a negociação de reivindicações, bem como a viabilização de objetivos, que conjugam ciência e energia nuclear.

13 Projeto de regimento interno do CNPq de 1954 e versões do regimento interno aprovado em 3 de março de 1955 pelo Conselho Deliberativo. - Rio de Janeiro, 1954 a 20 jun. 1955. 3 ed., 150 f. (Fundo CNPq - CNPq.T.1.1.004). 
Sobre as possíveis inspirações internacionais na concepção da instituição, a própria se pronuncia anos mais tarde:

\begin{abstract}
A implantação e também a atuação do CNPq foram influenciadas por outros modelos de organização e funcionamento de entidades congêneres em países economicamente mais avançados, como a França e os Estados Unidos. No entanto, o quadro do desenvolvimento econômico mostrava-se desfavorável à incorporação desses modelos, já que a pesquisa científica e tecnológica encontravase desvinculada do setor produtivo da economia. O outro fator desfavorável a essa transferência residia na dificuldade de se tentar programar o desenvolvimento da ciência e da tecnologia no País, numa época em que o próprio planejamento econômico ainda não era aceito nos vários segmentos do Governo e do setor em geral. (CONSELHO NACIONAL DE PESQUISA E DESENVOLVIMENTO CIENTÍFICO E TECNOLÓGICO, 1981b, s. p.).
\end{abstract}

Ao analisar o referido contexto, Domingos, por sua vez, lembra a conjugação de interesses diversos no âmbito político do capital científico, conforme o que estudamos de Bourdieu (2001; 2004).

A criação do $\mathrm{CNPq}$ não atende a interesses econômicos específicos; responde a uma confluência de vontades: a da comunidade científica excitada pelas revelações da Guerra, carente de reconhecimento e amparo material; a dos militares, ansiosos por um instrumento sem o qual estaria congelada a assimetria dos meios de defesa, o engenho nuclear; a de letrados urbanos de variados matizes ideológicos interessados na superação da economia agroexportadora e da dependência externa; a de industriais necessitados de novas tecnologias e, finalmente, a de governantes em busca de legitimidade por meio de acenos ao padrão moderno. (DOMINGOS, 2004, p. 23).

Alinhado à tendência nacional-desenvolvimentista, prossegue o mesmo autor, a instituição tem um programa nuclear autônomo, com política de compensações específicas, pelo menos durante a gestão de Álvaro Alberto. Essa perspectiva parece justificar o envio dos primeiros bolsistas do CNPq aos Estados Unidos, ao Canadá e à Europa, em defesa do campo da energia 
atômica, no âmbito das Ciências Biológicas ${ }^{14}$ (o que pode abrir uma hipótese quanto ao prestígio das Ciências Exatas no Brasil, já naquela época).

Romani (1982) lembra que essa instituição se propõe a planejar a atividade científica num contexto em que o próprio conceito de "planejamento" ainda não tinha sido incorporado ao discurso oficial sobre C\&T no âmbito do desenvolvimento econômico brasileiro.

Seja pelo papel de coordenação a ele atribuído, seja pelo fato de que ao ser instituído estivesse intimamente relacionado à questão nuclear - domínio explícito da segurança nacional - ou porque, ao constituir-se em órgão de fomento e coordenação da ciência e da tecnologia passaria a controlar não só a prática, mas sobretudo a ideologia do 'saber científico', elemento legitimador de poder, o fato é que o CNPq foi sempre revestido de caráter eminentemente político. (ROMANI, 1982, p. 140).

Outro aspecto considerado por essa autora é a defesa da liberdade e o não comprometimento do cientista com os fatores externos, alheios aos interesses científicos (ROMANI, 1982). Podemos relacionar essa perspectiva à lógica própria de funcionamento do campo científico, proposta por Bourdieu (2001), na qual o capital científico circula, ainda que predominantemente político, conforme apresentamos.

De acordo com Domingos, (2004), a proposta inicial do CNPq muda, com as mudanças de direção. Ele assinala, por exemplo, a gestão conservadora e avessa à mobilização política do mundo acadêmico e ao apoio aos cientistas sociais, de Christóvão Cardoso. Com vistas a enfatizar a C\&T, o CNPq passa por uma importante modificação na sua estrutura e nos seus objetivos (CONSELHO NACIONAL DE DESENVOLVIMENTO CIENTÍFICO E TECNOLÓGICO, 1981a; 1981b).

14 Discurso de Álvaro Alberto sobre a criação do CNPq e a exploração dos minérios radioativos no Brasil, na reunião do Conselho Nacional de Economia. Inclui texto contendo informações sobre o CNPq e sua atuação. - Rio de Janeiro, 31 jan. 1955. 2 d., 32 f. (Fundo CNPq CNPq.T.1.1.005). 
A instituição outrora reconhecida como "A casa do cientista" passa por dificuldades e crises. Na Ditadura, dedica-se ao apoio ao desenvolvimento da ciência, sob o domínio e o controle do Governo:

O ensino e a pesquisa tornam-se objeto de planejamento e contam com volume de recursos inéditos. Um grande sistema de pós-graduação é implantado, os salários e as condições de trabalho dos professores e pesquisadores são substancialmente melhorados; a participação da comunidade científica nas atividades da Capes e do CNPq é possibilitada pelo reconhecimento institucional das áreas do conhecimento e a subseqüente organização da avaliação do mérito científico por meio do julgamento pelos pares. (DOMINGOS, 2004, p. 26-27, grifos nossos).

O CNPq passa a compor, como órgão central, o sistema que organiza a C\&T no Brasil (BRASIL, 1972). É nesse contexto que a instituição se aproxima dos Estados Unidos. "Carecendo de técnicos para o gerenciamento de seus planos, o regime incentiva, por intermédio do CNPq e da Capes, a formação de planejadores e cientistas sociais voltados para o desenvolvimento" (DOMINGOS, 2004, p. 29).

Em 1975, são criados os comitês assessores, cujo propósito é "prestar assessoria ao CNPq nos assuntos da área de conhecimento de sua especialização, atendendo a solicitações ou por iniciativa própria". ${ }^{15}$ As suas duas competências são: 1) propor anualmente o documento "Avaliação \& Perspectivas", para a sua área de competência; 2) e propor ação fomentadora das solicitações de apoio à pesquisa e à formação de recursos humanos.

Domingos pondera sobre a sua relevância, lembrando que:

O comitê assessor, organizado por área do conhecimento, é o mecanismo-chave na mediação entre a vontade do Estado e a do produtor de conhecimento. Não por acaso, é adotado exatamente quando o regime militar vive seu momento de profundo desgaste e reconhece a necessidade de preparar a transição para a democracia. (DOMINGOS, 2004, p. 30).

15 Manual de Documentação Básica contendo resoluções normativas, estatutos e legislação institutiva do CNPq. - S. I., 1976 a 1978. 1 d., 291 f. (Fundo CNPq - CNPq.T.1.1.009). Resolução Normativa RN0V76 (entrou em vigor em $1^{\circ}$ de novembro de 1975). 
São 16 comitês assessores (CONSELHO NACIONAL DE DESENVOLVIMENTO CIENTÍFICO E TECNOLÓGICO, 1981b) ${ }^{16}$, ampliados para vinte (CONSELHO NACIONAL DE DESENVOLVIMENTO CIENTÍFICO E TECNOLÓGICO, 1981a) ${ }^{17}$ e, depois, para 26, em 1984 (CONSELHO NACIONAL DE PESQUISA E DESENVOLVIMENTO CIENTÍFICO E TECNOLÓGICO, 1984). ${ }^{18}$

16 Os comitês assessores eram: 1) Morfologia e Genética; 2) Bioquímica, Biofísica, Fisiologia, Imunologia, Microbiologia e Parasitologia; 3) Medicina Clínica, Saúde Pública e Nutrição, Farmacologia, Farmácia e Patologia; 4) Agronomia, Alimentos e Recursos Florestais; 5) Veterinária e Zootecnia; 6) Zoologia, Botânica e Ecologia; 7) Física e Astronomia; 8) Matemática; 9) Química; 10) Geociências; 11) Oceanografia; 12) Engenharia I (Engenharias Elétrica, Eletrônica e Ciência da Computação); 13) Engenharia II (Engenharia Civil e Arquitetura, Engenharias Naval, Mecânica, de Produção e Aeronáutica); 14) Engenharia III (Engenharias Metalúrgica, de Minas, de Materiais e Química); 15) Ciências Humanas (Psicologia, Filosofia, História, Arqueologia, Linguística e Letras/Educação, Direito, Administração, Urbanismo e Informação); 16) Ciências Sociais (Sociologia, Antropologia, Ciências Políticas, Economia, Demografia e Geografia).

17 Os comitês passam a ter a seguinte composição: 1) Morfologia, Genética, Microbiologia, Parasitologia e Imunologia; 2) Patologia, Medicina Experimental e Odontologia; 3) Bioquímica, Biofísica, Fisiologia e Farmacologia; 4) Saúde Pública, Medicina Preventiva e Nutrição; 5) Agronomia, Alimentos e Recursos Naturais; 6) Zoologia, Botânica e Ecologia; 7) Medicina Veterinária e Zootecnia; 8) Geociências; 9) Física e Astronomia; 10) Química; 11) Matemática; 12) Oceanografia; 13) Ciências da Computação; 14) Engenharia Elétrica, Eletrônica e Biomédica; 15) Engenharia Civil e Arquitetura; 16) Engenharia Química, Minas, Metalurgia e Materiais, e Nuclear; 17) Engenharia Mecânica, Naval, Aeronáutica e de Produção; 18) Economia, Administração, Demografia, Geografia, Urbanismo e Ciências da Informação; 19) Sociologia, Antropologia, Ciências Políticas, História, Arqueologia e Direito; 20) Psicologia, Filosofia, Educação, Letras e Linguística.

18 Os 26 comitês são: 1) Morfologia, Microbiologia, Parasitologia e Imunologia; 2) Genética; 3) Medicina, Odontologia, Enfermagem, Educação Física, Fisioterapia, Fonoaudiologia e Farmácia; 4) Bioquímica, Biofísica, Fisiologia e Farmacologia; 5) Saúde Pública, Medicina Preventiva e Nutrição; 6) Agronomia e Engenharia Florestal; 7) Engenharia Agrícola e Alimentos; 8) Zoologia, Botânica e Ecologia; 9) Medicina Veterinária e Zootecnia; 10) Geologia e Geografia Física; 11) Geofísica, Meteorologia e Geodésica; 12) Física e Astronomia; 13) 
Novamente, o Conselho se aproxima da França, inspirando-se no modelo dos laboratórios associados do CNRS (DOMINGOS, 2004).

Ao comparar as trajetórias de institucionalização dos conselhos nacionais de pesquisa na França e no Brasil, Motoyama e Nagamini (1996) observam, como ponto comum, o empreendimento de esforços da comunidade científica e tecnológica nos dois países. No mais, pontuam peculiaridades, como as especificidades dos contextos socioculturais, das diferenças entre o ativismo político dos cientistas franceses e o envolvimento político dos cientistas brasileiros, além do forte impacto da questão da energia nuclear na opinião pública brasileira, como o principal fator a ser considerado na criação do Conselho Nacional de Pesquisas no Brasil. Segundo eles,

O CNRS, surgido em 1939, vai servir como inspiração a algumas tentativas brasileiras para a criação do CNPq, que só vai ocorrer doze anos depois. Em repetidas condições, o órgão francês de apoio à pesquisa foi trazido à tona para fomentar as discussões em torno de um conselho nacional de pesquisas no Brasil. Contudo, a concretização do mesmo se faz de uma forma diferente daquela do CNRS. (MOTOYAMA; NAGAMINI, 1996, p.358).

Quanto às áreas do conhecimento, o CNPq tem a sua primeira Tabela de Áreas do Conhecimento (TAC) em 1976, embora a sua estrutura de base date dos anos 1950 (SOUZA, 2004). De acordo essa TAC, "A classificação das Áreas do Conhecimento tem por finalidade permitir ao CNPq e, eventualmente, a outros órgãos e instituições, sistematizar informações sobre 0 desenvolvimento científico e a formação de recursos humanos para a

Química; 14) Matemática e Estatística; 15) Oceanografia; 16) Ciências da Computação; 17) Engenharia Elétrica, Eletrônica e Biomédica; 18) Engenharia Civil; 19) Engenharia Química, de Minas, de Metalurgia e Materiais e Nuclear; 20) Engenharia Mecânica, Naval, Aeronáutica e de Produção; 21) Filosofia, Psicologia e História; 22) Antropologia, Arqueologia, Sociologia e Ciência Política; 23) Artes, Comunicação, Letras e Linguística; 24) Ciência da Informação, Direito, Serviço Social, Geografia Humana, Arquitetura e Urbanismo, Planejamento Urbano e Regional; 25) Economia, Demografia e Administração; 26) e Educação. 
pesquisa" (CONSELHO NACIONAL DE DESENVOLVIMENTO CIENTÍFICO E TECNOLÓGICO, 1978, p. 3).

Em 1978 a tabela é atualizada e, em 1982, áreas, subáreas e especialidades foram hierarquizadas dentro de cinco grandes áreas (CONSELHO NACIONAL DE DESENVOLVIMENTO CIENTÍFICO E TECNOLÓGICO; INSTITUTO BRASILEIRO DE INFORMAÇÃO EM CIÊNCIA E TECNOLOGIA, 1978). ${ }^{19}$

A TAC de 1984, elaborada durante o regime militar, envolve mais de 500 pesquisadores, em dezenas de reuniões. ${ }^{20}$ De acordo com o texto da sua apresentação, "A Classificação das Áreas do Conhecimento tem finalidade eminentemente prática, objetivando proporcionar aos órgãos que atuam em ciência e tecnologia uma maneira ágil e funcional de agregar suas informações" (CONSELHO NACIONAL DE DESENVOLVIMENTO CIENTÍFICO E TECNOLÓGICO, 1984). As classificações utilizadas pelas outras entidades nacionais são analisadas, bem como aquelas de entidades estrangeiras. Nessa $\mathrm{TAC}^{21}$, as áreas e subáreas são rearranjadas em oito grandes áreas (Ciências Exatas e da Terra; Ciências Biológicas; Engenharias; Ciências da Saúde; Ciências Agrárias; Ciências Sociais Aplicadas; Ciências Humanas; Linguística, Letras e Artes) e o nível das especialidades deixa de aparecer na sua forma impressa (CONSELHO NACIONAL DE DESENVOLVIMENTO CIENTÍFICO E TECNOLÓGICO, 1984).

19 SOUZA, Rosali Fernandez de. Tabelas de áreas do conhecimento: proposta de metodologia do trabalho de revisão. 2005. (Fundo CNPq)

20 As instituições diretamente envolvidas na elaboração do documento são: a CAPES, o CNPq, a Fundação de Amparo à Pesquisa do Estado do Rio Grande do Sul (FAPERGS), a Financiadora de Estudos e Projetos (FINEP), a Secretaria de Ensino Superior do Ministério da Indústria e do Comércio (STMMIC) e a Secretaria de Indústria e Comércio, Ciência e Tecnologia do Estado de São Paulo (CONSELHO NACIONAL DE DESENVOLVIMENTO CIENTÍFICO E TECNOLÓGICO, 1984).

${ }^{21}$ Áreas do conhecimento - classificação (1984?) (Fundo CNPq). 
Esta versão é revisada na década de 1990 (SOUZA, 2004) e passa por uma tentativa de revisão em 2005, que não se consolida. ${ }^{22}$ A tabela em vigor é hierarquicamente divida em quatro níveis: 1) grandes áreas; 2) áreas; 3) subáreas; 4) e especialidades. ${ }^{23}$

Podemos sintetizar as principais alterações das áreas do conhecimento do CNPq no quadro 1:

QUADRO: Estruturação das áreas do conhecimento pelo $\mathrm{CNPq}$

\begin{tabular}{|l|c|c|c|c|c|c|c|}
\hline \multicolumn{1}{|c|}{ DIVISÕES } & $\begin{array}{c}\mathbf{1 9 5 1 -} \\
\mathbf{1 9 6 6}\end{array}$ & $\mathbf{1 9 6 6}$ & $\mathbf{1 9 7 6}$ & TAC 1976 & $\begin{array}{c}\text { TAC } \\
\mathbf{1 9 8 2}\end{array}$ & $\begin{array}{c}\text { TAC } \\
\mathbf{1 9 8 4}\end{array}$ & $\begin{array}{c}\text { Proposta de } \\
\text { revisão da TAC } \\
\text { (2005) }\end{array}$ \\
\hline Grandes áreas & & & & $\begin{array}{c}\text { Não } \\
\text { apresenta }\end{array}$ & 5 & $8^{*}$ & 8 \\
\hline Áreas & 7 & 9 & 15 & 42 & 70 & 76 & 94 \\
\hline Subáreas & & & & & & 340 & 456 \\
\hline Especialidades & & & & & & $867^{* *}$ & $\begin{array}{c}\text { Não (lista } \\
\text { alfabética) }\end{array}$ \\
\hline
\end{tabular}

Fonte: Souza (2004; 2005;24 2008), Souza e Stumpf (2009), Romani (1982).

* Depois foi incluída outra grande área "Outros", com 23 itens listados em ordem alfabética (DOMINGOS; FERNANDEZ, 2005? ${ }^{25}$ ).

**À época da publicação da última TAC, as especialidades não foram detalhadas (CONSELHO NACIONAL DE DESENVOLVIMENTO CIENTÍFICO E TECNOLÓGICO, 1984).

22 Em 2005, o CNPq, a CAPES e a Financiadora de Estudos e Projetos (FINEP) compõem uma comissão especial de estudos para propor uma nova TAC, considerando a defasagem da tabela em vigor e a "forte tendência de interdisciplinaridade das áreas do conhecimento". Essa comissão deveria, em sintonia com as tendências internacionais e com a comunidade científica, estudar as profissões com base na Organização Internacional do Trabalho (OIT), mapear os problemas das grandes áreas e definir as bases epistemológicas para a nova tabela (Portaria conjunta do CNPq, CAPES e FINEP, de 02 de março de 2005).

23 Informações disponíveis em: <http://www.capes.gov.br/avaliacao/instrumentos-deapoio/tabela-de-areas-do-conhecimento-avaliacao>. Acesso em: 22 mar. 2016.

24 SOUZA, Rosali Fernandez de. Tabela de Áreas do Conhecimento: proposta de metodologia do trabalho de revisão. Fevereiro de 2005 - Fundo CNPq.

25 Construção da nova classificação das áreas do conhecimento: metodologia e direcionamentos, elaborado por Rosali Fernandez, para a $2^{\mathrm{a}}$ reunião da Comissão, de 31 de maio de 2005 - Fundo CNPq. 
Conquistando o reconhecimento de "esteio do Brasil moderno" (DOMINGOS, 2004, p. 40), o CNPq tem a sua importância sintetizada pelo mesmo estudioso:

Ao longo de sua trajetória, o Conselho, entre outras coisas, credencia e impulsiona programas de pós-graduação; reconhece formalmente novas áreas do conhecimento e fomenta a investigação de novos objetos estudos; incentiva o intercâmbio de pesquisadores e instituições, ampara publicações especializadas, equipa laboratórios e universidades, financia expedições, fortalece as agências estaduais de fomento e amplia o acesso da sociedade brasileira à cultura científica. (DOMINGOS, 2004, p.20).

\section{CONSIDERAÇÕES FINAIS}

O prestígio da cultura francesa perpassa grande parte dos diversos domínios do conhecimento no Brasil e talvez justifique a noção generalizada de que o CNRS teria inspirado a criação do CNPq. Ainda que esta noção não seja uma inverdade, ela não se concretiza na exclusividade dessa inspiração. Conforme constatamos em nossa pesquisa bibliográfica, outras instituições internacionais congêneres teriam influenciado o Conselho Nacional de Pesquisas no Brasil, especialmente dos Estados Unidos, do Canadá e do Reino Unido (ROMANI, 1982; MOTOYAMA, 1985; MOTOYAMA; NAGAMINI, 1996; ANDRADE, 1998).

Observamos, portanto, que ainda que diante dessas várias inspirações e tendo o CNRS como influência em diversos momentos e situações (ROMANI, 1982) - para aprender a percorrer o "caminho das pedras" na sua concepção e no seu estabelecimento, com a busca de articulação entre cientistas e políticos; para se inspirar na criação das suas primeiras seções (SBC) ou na valorização da Ciência Pura $(A B C)$; para amparar a Ciência por meio do estabelecimento de uma instituição estatal -, na perspectiva do prestígio internacional de suas congêneres, o CNPq se estabelece no Brasil conforme contextos, influências e relações políticas próprias, acomodando-se institucionalmente nos movimentos ditados pelo o que Bourdieu $(2001 ; 2004)$ chamaria de "capital científico temporal ou político", ou seja, aquele adquirido por estratégias políticas em 
instâncias temporariamente dominantes. Embora motivada internacionalmente e veemente defendida por um dos mentores do CNPq, a ideia de um Conselho Nacional de Pesquisas pautada no desenvolvimento de energia atômica não se concretiza. É a ideia mais ampla de o Estado amparar a ciência, por meio do estabelecimento de uma instituição, que ganha força, com a articulação de cientistas e intelectuais.

Atualmente, os conselhos nacionais de pesquisa dos países que mais teriam influenciado o Brasil têm perfis diferenciados e dinâmicos (como no Canadá e no Reino Unido, onde a pesquisa é associada à indústria e ao mundo do trabalho), o que dificulta uma comparação com a instituição brasileira.

Quanto à classificação das áreas do conhecimento, sem nos determos aos seus detalhes, verificamos que, desde a sua criação, o CNPq tem uma ampla proposta, anunciando a sua abrangência em qualquer domínio do conhecimento, embora, estruturalmente, se limite a alguns setores, inicialmente restritos às Ciências Exatas e às Tecnologias (somente em 1955 as Ciências Sociais passam a ser contempladas).

A conjugação de diferentes inspirações e das peculiaridades que consubstanciam o seu estabelecimento é, portanto, a tradução de aspectos políticos que perpassaram a concepção do Conselho Nacional de Pesquisas no Brasil, sua criação e seu desenvolvimento em contextos nacionais diversos, moldadas à luz de influências de prestígio internacional, de articulações pessoais (com destaque para os intelectuais) e de estratégias institucionais, as quais, segundo Domingos (2004), caracterizariam o CNPq, ao longo do tempo de uma "casa do cientista" a um "esteio do Brasil moderno".

\section{REFERÊNCIAS}

ANDRADE, Ana Maria Ribeiro de. História e fonte para a história do CNPq. In: MUSEU DE ASTRONOMIA E ARTES AFINS (MAST/CNPq). Arquivo CNPq (Acervo MAST): inventário sumário. Rio de Janeiro: MAST, 1998.

AZEVEDO, Fernando de (Org.). As ciências no Brasil. 2 ed. Rio de Janeiro: Editora UFRJ, 1994. 
BOURDIEU, Pierre. Science de la science et réflexivité: Cours du Collège de France 2000-2001. Paris: Raisons d'agir, 2001.

Os usos sociais da Ciência: por uma sociologia clínica do campo científico. Tradução Denice Barbara Catani. São Paulo: UNESP, 2004.

BRASIL. Lei n. 1310, de 15 de janeiro de 1951. Cria o Conselho Nacional de Pesquisas e dá outras providências. Rio de Janeiro, 1951 a 1975.7 d., 88f, 1 cópia. (Fundo CNPq - CNPq.T.1.1.002) - 1951a.

BRASIL. Decreto n. 29.433, de 04 de abril de 1951. Aprova o regulamento do Conselho Nacional de Pesquisas. Rio de Janeiro, 1951 a 1975.7 d., 88f, 1 cópia. (Fundo CNPq - CNPq.T.1.1.002) - 1951b.

BRASIL. Decreto n. 56.122, de 27 de abril de 1965. Aprova o Regulamento do Conselho Nacional de Pesquisas. Rio de Janeiro, 1951 a 1975.7 d., 88f, 1 cópia. (Fundo CNPq - CNPq.T.1.1.002) - 1965.

BRASIL. Decreto n. 70.553 de 17 de maio de 1972. Define áreas de competência no Setor de Ciência: e Tecnologia e dá outras providências Fundo CNPq (CNPq.T.1.1.006) - 1972.

CONSELHO NACIONAL DE DESENVOLVIMENTO CIENTÍFICO E TECNOLÓGICO; INSTITUTO BRASILEIRO DE INFORMAÇÃO EM CIÊNCIA E TECNOLOGIA. Classificação das áreas do conhecimento. Cadernos de Informação em Ciência e Tecnologia, n. 1, jun./1978.

CONSELHO NACIONAL DE PESQUISAS. O Conselho Nacional de Pesquisas: informações gerais e regulamentação do processo de concessão de auxílios para pesquisas. Rio de Janeiro: Conselho Nacional de Pesquisas, 1952.

CONSELHO NACIONAL DE PESQUISA E DESENVOLVIMENTO CIENTÍFICO E TECNOLÓGICO. CNPq: origens e perspectivas. 1 ed. Brasília: CNPq, 1981a.

CONSELHO NACIONAL DE PESQUISA E DESENVOLVIMENTO CIENTÍFICO E TECNOLÓGICO. CNPq: origens e perspectivas. 3 ed. Brasília: CNPq, 1981b.

CONSELHO NACIONAL DE PESQUISA E DESENVOLVIMENTO CIENTÍFICO E TECNOLÓGICO. CNPq: origens e perspectivas. 4 ed. Brasília: CNPq, 1984.

DOMINGOS, Manuel. A trajetória do CNPq. Acervo, Rio de Janeiro, v. 17, n. 2, p. 19-40, 2004.

MOTOYAMA, Shozo. A gênese do CNPq. Revista da Sociedade Brasileira de História da Ciência. São Paulo, n. 2, p. 27-46, jul./dez. 1985. 
MOTOYAMA, Shozo. Prelúdio para uma História: Ciência e Tecnologia no Brasil. São Paulo: Editora da Universidade de São Paulo, 2004.

MOTOYAMA, Shozo; NAGAMINI, Marilda. CNPq e CNRS: duas histórias numa perspectiva comparada (1996). In: HAMBURGER, Amélia Império. (et al). A ciência nas relações Brasil-França (1850-1950). São Paulo: Editora da Universidade de São Paulo; FAPESP, 1996, p. 331-359.

ROMANI, Jacqueline Pitangui. O Conselho Nacional de Pesquisas e Institucionalização da Pesquisa Científica no Brasil. In: SCHWARTZMAN, Simon (Org.). Universidades e instituições científicas no Rio de Janeiro. Brasília: CNPq, 1982, p. 137-167.

SCHWARTZMAN, Simon. Formação da comunidade científica no Brasil. São Paulo: Ed. Nacional; Rio de Janeiro: Financiadora de Estudos e Projetos, 1979. (vol. 2)

SOUZA, Rosali Fernandez de. Áreas do conhecimento. DataGramaZero: Revista de Ciência da Informação. Rio de Janeiro, v. 5, n. 2, abr. 2004.

A Ciência da Informação como área do conhecimento e de fomento no CNPq. In: Encontro Nacional de Ensino e Pesquisa em Informação, 8., Salvador, 2008. Anais... Salvador, 2008.

; STUMPF, Ida Regina Chitto. Ciência da Informação como área do conhecimento: abordagem no contexto da pesquisa e da Pós-graduação no Brasil. Perspectivas em Ciência da Informação, Belo Horizonte, v. 14, n. especial, p. 41-58, 2009

Title

The institutionalization of the Council for Research in Brazil: international historical inspirations and identity for the conception of the areas of knowledge

\begin{abstract}
Introduction: We consider the lack of historical data regarding the trajectory of the National Council for Research in Brazil, CNPq in the current Portuguese acronym, as well as the idea that the institution has been inspired by its French congener. Objective: This paper intends to present the historical inspirations in the international context, especially in France, and the formation of the institutional identity of this Council. Methodology: It is a bibliographical and documental research whose theoretical system of references are based on the concepts of "international prestige" and "scientific capital". Results: As for the results of this research study, we present a brief historical register of the research councils of the United States, Canada, United Kingdom and particularly France, as well as their current main divisions regarding the classifications of areas of knowledge. We further present the history of the conception, creation and development of $\mathrm{CNPq}$ and the areas of knowledge acknowledged by the institution over the years, debating the similarities that it bears to the international
\end{abstract}


councils, its influences - considering the international prestige of these institutions and its particularities, by means of the institutional and political scientific capital. Conclusions: We have reached the conclusion that political and institutional aspects prevail in the National Council for Research in Brazil, considering that the international inspirations are diverses and do not seem to translate into the institutional identity that lines up with the national context.

Keywords: National Council for Research. CNPq. Areas of knowledge. History of Science. Science and Technology.

\section{Titulo}

La institucionalización del Consejo de Investigación en Brasil: inspiraciones históricas internacionales e identidad para la concepción de las áreas del conocimiento

\section{RESUMEN}

Introducción: Considera la escasez de registros históricos sobre la trayectoria del Consejo Nacional de Investigación en Brasil, hoy CNPq, así como de la idea de que la institución habría sido inspirada en su homóloga francesa. Objetivo: Este artículo pretende presentar las inspiraciones históricas en el contexto internacional, especialmente en Francia, y la formación de la identidad institucional de este Consejo. Metodología: Se trata de una investigación bibliográfica y documental, cuyo marco teórico se basa en los conceptos de "prestigio internacional" y "capital científico". Resultados: Como resultados de esta investigación, se presenta un breve histórico de los centros de investigación de los Estados Unidos, Canadá, Reino Unido y, especialmente, de Francia, así como de sus principales divisiones actuales, relacionadas a las clasificaciones de las áreas del conocimiento. Se presenta, todavía, la trayectoria de concepción, creación y desarrollo del $\mathrm{CNPq}$, las áreas del conocimiento reconocidas por la institución a lo largo del tiempo, discutiendo aspectos de aproximación a los consejos internacionales, sus inspiraciones teniendo en vista el prestigio internacional de estas instituciones, y sus particularidades, mediante el capital científico político e institucional. Conclusiones: Concluí que los aspectos políticos e institucionales predominan en el establecimiento del Consejo Nacional de Investigación en Brasil, una vez que las inspiraciones internacionales son variadas y no parecen traducirse en la identidad institucional que se alinea con el contexto nacional.

Palabras clave: Consejo Nacional de Investigación. CNPq. Áreas del conocimiento. Historia de la Ciencia. Ciencia y Tecnología.

Recebido em: 23.06.2016

Aceito em: 13.12.2017 